\title{
Digital Technological Innovation and the International Political Economy
}

\author{
Irina Brass* and David J Hornsby* \\ i.brass@ucl.ac.uk $\quad$ d.hornsby@ucl.ac.uk \\ *Department of Science, Technology, Engineering and Public Policy (STEaPP) \\ University College London \\ Boston House, 36-38 Fitzroy Square, London, WIT 6EY, UK
}

\begin{abstract}
This chapter explores the main digital technological innovations currently associated with the Fourth Industrial Revolution - Artificial Intelligence (AI), Blockchain, and the Internet of Things (IoT) - and their effects on the international political economy. It reviews some of their main benefits and challenges to established structures of the global economy, such as international trade and production, or the monetary and financial system. The chapter highlights that the complex coupling, interdependencies and pervasiveness of these digital innovations disrupts the practice of international political economy on three dimensions: the established institutions that structure the international political economy; the distribution of authority between state and non-state actors; and the distribution of resources between and within developed and developing states.
\end{abstract}

\section{Introduction}

The premise of inquiry for this chapter is rooted in the technological transformations we hear about and are being exposed to on a daily basis. These technological shifts are sometimes celebrated for their potential to address some of the fundamental public policy challenges of our time, such as providing new ways to access health and education. Similarly, they are questioned for their capacity to produce disruptive effects to the way we organise our social and economic activities, challenging fundamental rights such as privacy or established patterns of employment and trade (OECD 2017a). One aspect that is rarely contested, though, is that these technological changes are already taking place and are here to stay.

We are thus no longer looking into the potential benefits and challenges of the "Fourth Industrial Revolution" (Schwab 2017). We are, in fact, living in it. The increased adoption of connected and intelligent objects coined the Internet of Things, the rise of the automatic enterprise, and the growing investment in cryptocurrencies are only some of the current trends that highlight the extent to which new digital transformations have penetrated core aspects of our lives. 
Several governments around the world are already weighing the benefits and challenges that these digital transformations bring to their citizens, economies and foreign relations. Political, business and social leaders are increasingly coming together in international fora such as the G20 and the World Economic Forum (WEF) to discuss coordinated policies that would enable their societies and economies to maximise the benefits of these technological changes, while minimising their risks (G20 2017; OECD 2017b). Thus, there is increasing recognition that the technologies and processes that underpin these digital transformations, as well as their socioeconomic consequences, are not confined to state boundaries and jurisdictions.

This chapter considers the disruptive role that emerging digital technologies and processes play in the governance and functioning of the international political economy. The chapter focuses on three main digital innovations: artificial intelligence, blockchain and the Internet of Things (IoT). We refer to them as disruptive digital innovations - rather than disruptive technologies - because they are underpinned by several technologies and processes, which taken together, create new socio-economic patterns that affect the distribution of resources and power across the actors and structures that currently define the international political economy.

Connecting technology and disruption is rooted in the conceptual perspective of Joseph Schumpeter and his ideas related to innovation and "creative destruction". Schumpeter argued that technological innovation disrupts the organisation of society, politics, and the economy as it changes the conditions under which society operates (Schumpeter 1939). However, disruption theories do not focus solely on the undesirable consequences of innovation, such as market imbalances or suboptimal social outcomes. Rather, economies and societies are seen as constantly producing "disruptive innovations", which in turn allow for business, social and political regeneration (Christensen et al. 2016). Thus, this chapter aligns technology closely with the evolution of the international political economy, as a key factor in the creative reorganisation of the complex socio-economic systems that underpin it.

We begin the chapter by looking at the relationship between technology and the international political economy from a historical perspective. We adopt the "Four Industrial Revolutions" model proposed by Klaus Schwab to highlight the extent to which digital innovations contribute to shifts that account to a new industrial revolution (Schwab 2017). We then explore in more depth how each of these digital innovations disrupts the practice of international political economy, focusing on three main dimensions: a) the main regimes - understood as established patterns of cooperation - that currently structure the international political economy; b) the distribution of authority between state and non-state actors; c) the distribution of resources between and within developed and developing states. 


\section{Technology and the IPE in Practice}

To say that technology has fundamentally changed international affairs is not an understatement. The process of diplomacy and finance used to be slow and dependent on the delivery of physical communications, namely letters - that could take weeks to receive and were subject to getting lost, damaged or even tampered with. Access to information was highly restricted and controlled. Today, access to information is almost instantaneous with the advent of the Internet and digital tools that assist in deciphering and organising information in microseconds. The rapid collection of data and transfer of information are currently underpinning most structures of the international political economy, from global production chains, to the monetary and finance system, to foreign investment flows, or the transfer and protection of intellectual property.

Technology has also been instrumental in how the international political economy has evolved, often disrupting traditional practices and structures that foster economic growth and how states and non-state actors interact. Whilst it is beyond the focus of this chapter to go in depth into the evolution of the international political economy, it is worth noting how technology has been integral to the development of the world economy at various points. For conceptual ease, it is possible to connect technology to economic development over four periods. These periods are commonly referred to as "industrial revolutions".

\section{First Industrial Revolution (1760-1840)}

The First Industrial Revolution started in the late 1800s with the advent of technologies such as the steam engine that started the industrialisation and urbanisation of British and European societies, which had been largely agrarian and rural until this point. The steam engine enabled the mechanisation of production for things like textiles that increased supply and availability, making goods more readily accessible and cheaper to consumers. Technologies in this era also improved the capacity for movement of peoples and goods, cutting transit times, as well as the development of faster mechanised iron production processes - a key element for engineering, such as building bridges and buildings. In comparison to today, the technological development of this era is basic and simple, but the technology developed in this period underpins the contemporary economy and fundamentally shaped how states interact.

\section{Second Industrial Revolution (1870-1914)}

The Second Industrial Revolution is underpinned by technological developments such as the lightbulb and electrification, the telephone, and the combustion engine. These technological developments enabled a widespread adoption of machine-based production processes which has improved the quality and rate at which goods are produced. Further, this revolution 
introduced technologies that enabled the mass movement of people - connecting communities once remote and removed from each other. In particular the widespread electrification of communities and use of machine tools in production resulted in a real surge in economic growth as production times and the capacity to transport goods over further distances was reduced, facilitating faster international trade and spurring an interconnectedness between states. Here, technologies developed and assisted the process of globalisation.

\section{Third Industrial Revolution (1947-2010)}

The Third Industrial Revolution is often called the Digital Revolution as this period saw the emergence of the personal computer, the internet, and information communication technologies (ICT) like mobile phones. Based on the development of the digital circuit, this moment of technological change, which started in the latter half of the $20^{\text {th }}$ century, fundamentally reshaped the structure of the economy on a number of levels. It has made it easier for private enterprise to reach broader markets, it has quickened the flow of information and money between individuals, institutions and states, and it has expanded the types of services that are available to consumers. As well, it has had a significant impact on the production process with the introduction of automation that has revolutionised how the assembly line works. In essence, the digital revolution has influenced the process of globalisation by reducing physical and geographical barriers between economies and societies - enabling a greater degree of interconnectedness across states.

\section{Fourth Industrial Revolution (2010-present)}

The Fourth Industrial Revolution is a moment that many believe is upon us and is speculated to have significant implications not just for the global economy but also for the distribution of political and socio-economic authority. Klaus Schwab famously wrote (Schwab n.d.):

\footnotetext{
"The First Industrial Revolution used water and steam power to mechanize production. The Second used electric power to create mass production. The Third used electronics and information technology to automate production. Now a Fourth Industrial Revolution is building on the Third, the digital revolution that has been occurring since the middle of the last century. It is characterized by a fusion of technologies that is blurring the lines between the physical, digital, and biological spheres."
}

The Fourth Industrial Revolution promises to significantly reshape the global economy as new technologies change how production and consumption take place - moving beyond simple automation to technologies that maintain a degree of intelligence or rather a capacity to anticipate preferences or respond to defined problems, are small in scale, interconnected, 
disrupt traditional systems of governance and regulation, and even turn ways in which value is assigned, such as currencies, on their head. Some contemporary examples of how these innovations influence the practice and structure of international economic flows and politics are: Artificial Intelligence (AI), Blockchain, and the Internet of Things (IoT).

\section{Emerging Digital Innovations and Their Disruptive Effects on IPE}

\section{Artificial Intelligence}

The advent of artificial intelligence (AI) maintains significant implications for the international political economy. AI is intelligence displayed by a computer or machine that mimics the learning or problem-solving processes that humans undertake. AI first came to prominence with the chess playing computer - Deep Blue - that famously defeated then world champion Gary Kasparov in 1996. Since then, AI has developed and become more sophisticated and is being applied in a range of contexts from processing and understanding complex datasets, to military simulations and games, to autonomous vehicles. Most importantly, with the increasing use of machine learning algorithms and rule-based digital processes and systems, AI is developing more natural intelligence skills such as seeing, learning, reasoning or formulating and executing plans (Nau 2009).

Underpinning AI are algorithms that apply a set of rules and parameters under which the AI machine operates. This is why AI, at the moment, can only mimic learning and problem solving, as algorithms need to be pre-defined and are constrained in the number of rules and parameters they contain. That said, they are becoming more sophisticated and have enabled AI to be more widespread in application. One area where AI has had an impact on the international political economy is in stock trading. Here, AI has fundamentally reshaped how markets function, as algorithms have made it easier and quicker to understand demand and supply at an individualised level. Promoting the use of AI in market trading is believed to make behaviour more predictable, reducing human error or irrational consequences resulting in more efficient functioning of market activities.

The application of AI to many functions within the international political economy seems endless, but there is a current debate on whether AI threatens to replace humans in the workplace or will result in a new set of job opportunities to emerge. The response is likely that AI will disrupt job structures at multiple levels, including 'white collar' jobs performing professional and administrative tasks, but that it will also create opportunities for the workforce to upgrade its overall skillset. Klaus Schwab, the founder of the World Economic Forum, believes that low skilled/low paying jobs are particularly at threat from automation, which 
combines $\mathrm{AI}$ and robotics, and will increasingly require a reconfiguration of skills between machines and humans. To adapt to this will require a shift in how education is structured, particularly at the tertiary level. Arvanitakis and Hornsby (2016) argue that that the potential disruption posed by AI, and other similar technologies, requires universities in particular to shift their focus from primarily delivering disciplinary content to fostering skills that enable graduates to adapt to changing socio-economic forces.

\section{The Automatic Enterprise}

An emerging application of $\mathrm{AI}$ is in the development of the 'automatic enterprise', through the implementation of autonomous machines and systems in production and distribution processes. One example of this transformation has taken place in retail and warehouse management, where human and machines, such as robotic shelves, work in collaboration to ensure that storage space is effectively utilised and that packages are efficiently distributed across the warehouse in relation to their delivery time and location (Knight 2015). However, as enterprises become more automated, the impact on employment and new skills development becomes more acute. This is why multinational enterprises operating in both developed and developing countries are under more pressure to invest in new models of social corporate responsibility, which include training their workforce to manage and work alongside robots and artificial decision-making processes, as well as new social contract models that support the role that states have traditionally played in educating their population (UNIDO 2016; OECD 2017a).

The implications of AI on the labour market also pose particular problems for international security, stability, and development particularly in regions and states that are not industrialised or maintain a significant degree of inequality. If production processes become fully automated and run by intelligent machines, the space for economic development to take place through using low skilled workforces in the production of goods will become displaced, further marginalising the poor. Without considerable opportunities for economic development, social unrest and conflict can result, causing political instability and insecurity at the global level. Given the relationship between poverty, political stability, and violent conflict, it would not be a far stretch to imagine a world that is more unsafe if the opportunities of AI are not considered against processes and needs of developing countries or regions.

\section{Blockchain}

Blockchain is another example of digital innovation that gives real meaning to the potential impact of the Fourth Industrial Revolution. Blockchain is a distributed, peer-to-peer system 
that records and structures digital transactions in blocks of data that can be shared across a network of computers without the need for a central authority or trusted third party to control it.

\footnotetext{
"In essence, it is a shared, trusted, public ledger that everyone can inspect, but which no single user controls. The participants in a blockchain system collectively keep the ledger up to date: it can be amended only according to strict rules and by general agreement". (The Economist 2015)
}

Thus, one of the benefits of blockchain is that it allows for peer-to-peer transactions to emerge without the presence of a central clearinghouse. Originally developed to track and account for cryptocurrencies (see below), the application of blockchain maintains potential to revolutionise how contracts, records, and other forms of transactional information is kept. And, because blockchains incorporate digital encryption technologies for data transmission, algorithms, and time-stamping technologies to validate transactions, they provide a degree of security and transparency to record keeping, improving trust in economic transactions (Campbell-Verduyn 2017, 1).

Blockchain technology is already having a significant effect on the international political economy. Fundamentally, it challenges centralisation, understood as the hierarchical distribution of authority within and between states that has driven and supported the national and international flow of capital. For instance, blockchain can be used to transfer property ownership without the need for a central institution, such a bank or a land registry, to clear, monitor and record the process. The ability to record property rights on a public blockchain is perceived as having great potential for institutional capacity building in developing countries, where public record-keeping can be weak. Given the transparent nature of the blockchain, it could reduce property title fraud (Scott, Loonam, and Kumar 2017, 425). By distributing and noting transactions in each of the nodes of this horizontally-maintained ledger, the potential for fraudulent behaviour by one individual or organisation becomes less possible, as information is shared and stored across the system. However, the application of blockchain in land registry can also highlight some of the disruptive effects of this innovation. On the one hand, blockchain has the potential to strengthen state capacity through decentralised and transparent public record keeping, which reduces the financial burden to support the administrative apparatus of the state. On the other hand, blockchain creates competition in activities that have traditionally been within the remit of the sovereign state, thus challenging the authority of a key actor in international relations.

Because transactions using public blockchain are, ultimately, legal agreements that can be executed without intermediaries who set, monitor or ensure compliance with the terms of the 
contract, blockchain can be applied to a number of transactions, from issuing insurance policies to financial trading. These examples can also showcase the disruptive effects of blockchain on the international political economy. On the one hand, blockchain enables a more efficient, transparent and cost-effective exchange of capital, while also reducing information asymmetries between individuals, regulators and financial institutions in the international monetary and financial system. On the other hand, because blockchain is an anonymity-based technology, it can be used to circumvent the current rules and practices that define the international financial system, contributing to speculative high frequency trading and the creation of dark pools (Chiu 2016). Thus, in international financial markets, blockchain can both enable and obstruct transparent trading.

Lastly, blockchain can contribute to the creation of transnational social impact, enhancing the corporate social responsibility of private enterprises, and it has already been identified as having potential to improve the governance of complex supply chains through ethical sourcing (Al-Saqaf and Seidler 2017). For instance, in the context of mining and conflict diamonds, a technology start-up is using blockchain to verify, protect and warrant the ethical provenance of diamonds, as part of international efforts to reduce the number of conflict diamonds in circulation. ${ }^{1}$ In this sense, blockchain is being mobilised towards the ends of ethical international trade agreements and regimes such as the Kimberley Process Certification Scheme (KPCS), promoting ethical corporate behaviour and addressing the transnational trafficking of natural commodities (Hale and Held 2011, chap. 38). However, blockchain systems raise concerns about the anonymity of the code and verifying protocols that ultimately ensure its reliability and transparency. Like other digital technologies, blockchain relies on software that is vulnerable to cybersecurity breaches and requires constant patching and strong vulnerability management policies. Equally, while blockchain code is largely open source and transparent, its use might not always be, posing real legal and ethical concerns about the traceability and trustworthiness of online transactions, potentially requiring new legal institutions to define and implement liability in international transactions (Reed et al. 2017).

\section{Cryptocurrencies}

An emerging outcome of the prevalence of blockchain is the development of cryptocurrencies, such as Bitcoin or Etherium. Cryptocurrency is a digital currency that is not connected or supported by a state. It consists of monetary tokens whose circulation is being recorded in a distributed public database (ledger) that keeps track of transactions in a transparent manner. Scott et al $(2017,423)$ note that cryptocurrencies "suggest a commitment to principles like decentralization, social solidarity, and disintermediation", standing in contrast "to the

\footnotetext{
${ }^{1}$ Everledger uses blockchain, smart contracts and machine vision to authenticate and protect the provenance of high value assets.
} 
centralized and asymmetric power relations of the traditional financial sector". Because the issuing, control and management of money and credit has been a recognised source of authority and political struggle in international relations (Ravenhill 2016, chap. 8), cryptocurrencies challenge the fundamental distribution of power in the international political economy.

At first, cryptocurrencies such as Bitcoin were not perceived as a threat to the sources of authority and the structure of the international monetary system. Instead, they were regarded as exchange tokens in confined transnational 'cryptocommunities'. However, due to a number of critical events, such as the collapse of established financial institutions in the aftermaths of the financial crisis, cryptocurrencies became accepted forms of payment for sharing economy services provided through online platforms such as AirBnB and Uber (Campbell-Verduyn 2017). In addition, as online retailers and investment banks integrated blockchain into their operations, they also began developing their own cryptocurrencies and started trading them in digital marketplaces. This evolution has led scholars of international affairs to conclude that "[B]itcoin and blockchain technologies became increasingly integrated into the very global economic system that their earliest developers had explicitly sought to provide alternatives to" (Campbell-Verduyn 2017, 2).

Confirming the disruptive effects of these digital innovations on the international monetary system, the current Managing Director of the International Monetary Fund (IMF), Christine Lagarde, noted that cryptocurrencies could reshape currency markets and international investment in reserve currencies (Lagarde 2017):

"For instance, think of countries with weak institutions and unstable national currencies. Instead of adopting the currency of another country - such as the dollar - some of these economies might see a growing use of virtual currencies. Call it dollarization 2.0. [...] For instance, they could be issued one-for-one for dollars, or a stable basket of currencies. Issuance could be fully transparent, governed by a credible, pre-defined rule, an algorithm that can be monitored...or even a 'smart rule' that might reflect changing macroeconomic circumstances".

In part, the disruptive effects of this innovation on the global economy are already seen. Because, at present, there is no central bank or government that backs the value of cryptocurrencies, those who invest in it undertake significant risk, as it relies solely on market forces to interpret and determine its value. This poses a number of threats, some of which are already visible (Scott, Loonam, and Kumar 2017): the high volatility of cryptocurrencies (fluctuating from 10 to over 800 tokens vis-à-vis average currency fluctuations between 13 and 166 dollars over the same period); encouraging hoarding behaviour (which is more problematic if market participants borrow state-backed currencies to invest in cryptocurrencies); or hacking 
into private wallets or digital currency exchanges (as it has recently happened to the Japanese digital currency exchange) (BBC News 2018).

Given that cryptocurrencies are essentially 'empty assets', their disruptive effects can be quite remarkable. By 'empty assets' we mean that there is no value beyond what people are willing to pay for them. Bacon et al. (2017) call them a:

"technological construct, which has value only to the extent that individuals are prepared to pay currently registered holders of BitCoins for transfer of the entitlement. If for some reason the system ceased to operate, all the assets would just disappear and holders would have no legal claim upon any person. If the encryption technology used had a flaw, so that unlimited BitCoins could be created, the value of each BitCoin would plummet to zero. Within the walled garden of the system, the law has no role to play."

In this context, it should come as no surprise that states and international organisations that have contributed to the current design and management of the international monetary and finance system are increasingly preoccupied with the status of cryptocurrencies in the global economy. At present, there are at least three pathways that can be identified, each with potential to disrupt the current organisation, principles and practices that define the international monetary and finance system. A first pathway would be to maintain the status quo, which could result in the increasing transfer of cryptocurrency risk into the real economy, as more goods and services are being purchased with it. Also, given the anonymity of the distributed ledgers that support cryptocurrencies, illegitimate activities such as money laundering and the creation of dark pools could disrupt the stability and transparency of financial transactions, causing financial bubbles and even a new financial crisis.

A second pathway is for the regulation of cryptocurrencies to emerge, either on a state-by-state basis or through transnational coordination. At the moment, an increasing number of countries such as Russia, China, Israel, the US, and the EU are proposing regulatory frameworks to either govern or ban digital currency markets and platforms (Liao 2017; BBC News 2017; Barkho 2018; ESMA 2017). There is, however, an inherent limitation with this approach, whereby cryptocurrency activity could move to unregulated markets, encouraging a regulatory race-tothe-bottom.

A third pathway is for cryptocurrencies to become a formalised means of exchange through existing international monetary agreements or recognition by established international monetary organisations. Recently, the IMF Managing Director pointed at the IMF's Special Drawing Rights (SDR) - an international reserve asset created by the IMF in the late 1960s to supplement members' reserves - as a potential avenue to apply blockchain technology on . 
This could lead to the formalisation of blockchain systems in the current structure of the international monetary system, but could also have negative effects on state and non-state actors who restrictively regulate these innovations in their national jurisdictions.

Regardless of the future pathway that blockchain and cryptocurrencies might take, there is clear indication that they challenge the central role that states have played in the creation of the current international monetary and finance system. The three pathways outlined above also reflect the new trade-offs that these digital innovations bring to the organisation of the international political economy. Whereas, in the past, authority has been contested between states, multinational financial institutions and international organisations, cryptocurrencies bring individuals and online communities into this process. How this process of decentralisation will influence international or even national monetary regulation remains unclear, but undoubtedly significant.

\section{The Internet of Things}

The Internet of Things (IoT) is the final digital innovation explored here for its disruptive effects on the current organisation of the international political economy. The IoT is an innovation characterised by embedding sensing (data capturing), communication, data processing and actuation techniques into physical objects and infrastructures, leading to the increased convergence of their physical and digital dimensions. In short, "the IoT embeds physical objects in information flows and thereby makes them 'smarter' (OECD 2017a, 88)."

The IoT is increasingly applied to a number of domains, each with their own domestic and international governance structures, from consumer goods (e.g. toys, home appliances, wearables), to medical devices, to transport systems (e.g. smart traffic systems, connected and autonomous vehicles) and critical infrastructure management (e.g. energy, water and waste management). Thus, the IoT ecosystem is characterised by "a proliferation of visible and hidden sensors that collect and transmit data; systems that interpret and make use of the aggregate information; and actuators that, on the basis of this information, take action without direct human intervention" (Tanczer et al. forthcoming).

Because IoT ecosystems integrate several digital technologies and processes, such as AI and blockchain, they create highly complex and connected infrastructures which blur the lines between information and communication technologies, the Internet as the global infrastructure that underpins it, and the production, distribution and management of goods and services. For instance, IoT is seen as enabling business transformations that change supply chain management through asset tracking and new delivery logistics, having an impact on the global 
production and distribution of goods and services and, subsequently, on current international trade patterns (Meola 2016).

The benefits and challenges of the IoT are increasingly capturing the attention of governments around the world. On the one hand, IoT is perceived as enabling socio-economic progress, by facilitating more customised, efficient production processes (industrial IoT), enabling forward planning by uncovering structural weaknesses in critical infrastructures, or responding to the challenges of an ageing population through personalised medicine and increased mobility. On the other hand, its public acceptance is challenged by the data protection and cybersecurity vulnerabilities that have been exposed in IoT devices and systems. These concerns are increasingly putting pressures on governments to establish a baseline of data protection and cybersecurity for IoT devices and systems, and to push these minimum specifications at regional and international level (US FTC 2015; ENISA 2017; US Senate 2017).

\section{IoT in Consumer Goods}

The IoT raises critical security and safety concerns due to its increased deployment in national infrastructure management systems in the utility and transport sectors, with potentially catastrophic consequences for the national security of sovereign states. However, an equally challenging area for the international political economy is the exponential rise of 'smart' consumer goods - such as connected TVs, home appliances, security cameras or home hubs that are increasingly deployed in private environments, collect more and more data about our patterns of life and communicate this data among themselves, sometimes without our awareness. In fact, smart consumer goods are currently projected as leading the global adoption of IoT by 2020 (Gartner 2017).

Mass market consumer goods have been relying on global supply chains, with products being manufactured, assembled and distributed around the world. This globalisation of supply chains has also manifested in low margins for manufacturers, who are increasingly embedding smart technologies into their products, in order to gain competitive advantage. However, most of these smart products have limited inbuilt data protection and cybersecurity features, and are very rarely supported through their lifecycle with vulnerability management policies, because cybersecurity translates into high sunk costs for manufacturers, service providers and retailers (Brass et al. 2017). These commercial practices translate into a global collective action problem, whereby most entities in the supply chain are disincentivised to implement cybersecurity standards, and insecure consumer products are increasingly disseminated across global markets. The negative consequences of these practices were felt in 2016, when a large number of insecure IoT consumer products, located all over the world, were compromised and 
utilised in the most powerful Distributed Denial of Service (DDoS) experienced thus far, bringing down large DNS servers in the US and Europe (Woolf 2016).

The rapid proliferation of IoT brings several challenges to the current structure of the global political economy, which has thus far been organised in discrete governance regimes for international trade in goods, information and communication technologies (ICTs), cybersecurity, data governance and international safety standards. Because IoT security spills over into each of these domains, it puts increasing pressures on governments and industry to set minimum standards that cut across these regimes (Brass et al. forthcoming). As the IoT becomes more embedded into our daily lives, with consequences for individual, state and global safety and security, it also requires a reconfiguration of politico-economic interests and institutional practices in the international political economy, which has traditionally managed supply chain processes, ICT interoperability, consumer protection and information security and in discrete regimes.

\section{Conclusions}

The innovations present in the Fourth Industrial Revolution raise particular issues for the international political economy, as they cover areas not presently regulated or included in international cooperation efforts. This chapter has shown that, although the technologies and processes presented in the Fourth Industrial Revolution are not new, it is their increased coupling, interdependencies and pervasiveness that challenge the distribution of authority and institutional structures that underpin our global political economy. Taken together, these digital innovations create new system-of-systems whose dynamics are only now starting to be explored. Thus, as also noted by Nick Bernard in Chapter X of this handbook, the consequences of this increasing "turn to technology" for meeting policy goals are not currently fully understood.

What are the ethical ramifications associated with the growing use of algorithms to perform international financial transactions? Or how should manufacturers of smart toys address the potential for hackers to access the personal information of children; or to utilise low security mass market products in order to compromise the integrity of the global infrastructure that is the Internet and the vast number of services that rely on it? All of these questions pose significant challenges for the international political economy, for how it evolves and how it shapes and reshapes power and resource distribution between state and non-state actors in the future. 
In addition, technology and labour have always had a difficult relationship. It is often assumed that technology replaces labour and destroys jobs, when often it displaces jobs in one area and creates new ones in others. That said, the implications of emerging digital innovations appear to be more severe than in previous 'industrial revolutions', requiring businesses and governments to rethink their social responsibility and collaborate closely in order to put forward new social contract models. Thus, consideration will need to be given around what value these new innovations have if they exacerbate inequalities, rather than serving to benefit society.

\section{References}

Al-Saqaf, Walid, and Nicolas Seidler. 2017. 'Blockchain Technology for Social Impact: Opportunities and Challenges Ahead'. Journal of Cyber Policy 2 (3): 338-354.

Arvanitakis, James, and David Hornsby. 2016. Universities, the Citizen Scholar and the Future of $\mid$ J. Arvanitakis | Palgrave Macmillan. //www.palgrave.com/br/book/9781137538680.

Bacon, Jean, Johan David Michels, Christopher Millard, and Jatinder Singh. 2017. 'Blockchain Demystified'. SSRN Scholarly Paper ID 3091218. Rochester, NY: Social Science Research Network. https://papers.ssrn.com/abstract=3091218.

Barkho, Gabriela. 2018. 'Why a Top Cryptocurrency Exchange Is Technically Illegal in New York City'. Inverse. 17 January 2018. https://www.inverse.com/article/40144binance-bitlicense-bitcoin-cryptocurrency-exchange-new-york-city.

BBC News. 2017. 'China Shutting down Bitcoin Exchanges'. BBC News, 19 September 2017, sec. Business. http://www.bbc.co.uk/news/business-41320568. 2018. 'Biggest Ever Digital Currency “Theft”', 27 January 2018, sec. Asia. http://www.bbc.co.uk/news/world-asia-42845505.

Brass, Irina, Leonie Tanczer, Madeline Carr, and Jason Blackstock. 2017. 'Regulating IoT: Enabling or Disabling the Capacity of the Internet of Things?' CARR Risk and Regulation Magazine 33 (August). http://www.lse.ac.uk/accounting/CARR/pdf/Risk\&Regulation/r\&r33/riskandregulation-33-web.pdf.

Brass, Irina, Leonie Tanczer, Madeline Carr, Miles Elsden, and Jason Blackstock. forthcoming. 'Standardising a Moving Target: The Development and Evolution of IoT Security Standards'. In IET Conference Proceedings. https://events.theiet.org/petras/programme.cfm.

Campbell-Verduyn, Malcolm. 2017. Bitcoin and Beyond: Cryptocurrencies, Blockchains, and Global Governance. Routledge.

Chiu, Iris H-Y. 2016. 'Fintech and Disruptive Business Models in Financial Products, Intermediation and Markets - Policy Implications for Financial Regulators'. Journal of Technology Law \& Policy 21: 55-112.

Christensen, Clayton M., Rory McDonald, Elizabeth J. Altman, and Jonathan Palmer. 2016. Disruptive Innovation: Intellectual History and Future Paths. Harvard Business School. http://www.hbs.edu/faculty/Publication\%20Files/17-057_2059672c-e9fb4df9-9f3e-2654b9b1c2a9.pdf.

ENISA. 2017. 'Baseline Security Recommendations for IoT in the Context of Critical Information Infrastructure'. https://www.enisa.europa.eu/publications/baselinesecurity-recommendations-for-iot. 
ESMA. 2017. 'ESMA Alerts Investors to the High Risks of Initial Coin Offerings (ICOs)'. 13 November 2017. https://www.esma.europa.eu/sites/default/files/library/esma50-157829_ico_statement_investors.pdf.

G20. 2017. 'Shaping Digitalisation at Global Level'. 2017. https://www.de.digital/DIGITAL/Redaktion/EN/Dossier/g20-shaping-digitalisationat-global-level.html.

Gartner. 2017. 'Gartner Says 8.4 Billion Connected'. 2 July 2017. https://www.gartner.com/newsroom/id/3598917.

Hale, Thomas, and David Held. 2011. Handbook of Transnational Governance: Institutions and Innovations / Edited by Thomas Hale and David Held. Cambridge: Polity Press.

Knight, Will. 2015. 'At Amazon Warehouses, Humans and Machines Work in Frenetic Harmony’. MIT Technology Review. 2015. https://www.technologyreview.com/s/538601/inside-amazons-warehouse-humanrobot-symbiosis/.

Lagarde, Christine. 2017. 'Central Banking and Fintech-A Brave New World? Bank of England Conference.' IMF. 29 September 2017. https://www.imf.org/en/News/Articles/2017/09/28/sp092917-central-banking-andfintech-a-brave-new-world.

Liao, Shannon. 2017. 'Inside Russia's Love-Hate Relationship with Bitcoin'. The Verge. 31 October 2017. https://www.theverge.com/2017/10/31/16387042/russia-putin-bitcoinregulation-ethereum-blockchain-technology.

Meola, Andrew Meola, Business. 2016. 'How IoT Logistics Will Revolutionize Supply Chain Management'. Business Insider. 21 December 2016. http://uk.businessinsider.com/internet-of-things-logistics-supply-chain-management2016-10.

Nau, Dana S. 2009. 'Artificial Intelligence and Automation'. In Springer Handbook of Automation, 249-68. Springer, Berlin, Heidelberg. https://doi.org/10.1007/978-3-54078831-7_14.

OECD. 2017a. The Next Production Revolution: Implications for Governments and Business. OECD Publishing. https://doi.org/10.1787/9789264271036-en. - 2017b. 'Key Issues for Digital Transformation in the G20'. https://www.oecd.org/g20/key-issues-for-digital-transformation-in-the-g20.pdf.

Ravenhill, John, ed. 2016. Global Political Economy. Fifth Edition. Oxford, New York: Oxford University Press.

Reed, Chris, Umamahesh Sathyanarayan, Shuhui Ruan, and Justine Collins. 2017. 'Beyond Bitcoin - Legal Impurities and Off-Chain Assets'. SSRN Scholarly Paper ID 3058945. Rochester, NY: Social Science Research Network. https://papers.ssrn.com/abstract=3058945.

Schumpeter, Joseph Alois. 1939. Business Cycles: A Theoretical, Historical, and Statistical Analysis of the Capitalist Process. Martino Pub.

Schwab, Klaus. 2017. The Fourth Industrial Revolution. Penguin UK. . n.d. 'The Fourth Industrial Revolution: What It Means and How to Respond'. World Economic Forum. Accessed 31 January 2018. https://www.weforum.org/agenda/2016/01/the-fourth-industrial-revolution-what-itmeans-and-how-to-respond/.

Scott, Brett, John Loonam, and Vikas Kumar. 2017. 'Exploring the Rise of Blockchain Technology: Towards Distributed Collaborative Organizations'. Strategic Change 26 (5): 423-28. https://doi.org/10.1002/jsc.2142. 
Tanczer, Leonie, Irina Brass, Miles Elsden, Madeline Carr, and Jason Blackstock. forthcoming. 'The United Kingdom's Emerging Internet of Things (IoT) Policy and Legislative Landscape'. In Rewired: Cybersecurity Governance. Wiley.

The Economist. 2015. 'The Promise of the Blockchain: The Trust Machine.' The Economist, 31 October 2015. https://www.economist.com/news/leaders/21677198-technologybehind-bitcoin-could-transform-how-economy-works-trust-machine.

UNIDO. 2016. 'Industry 4.0 Opportunities and Challenges of the New Industrial Revolution for Developing Countries and Economies in Transition. Panel Discussion.' 2016. https://www.unido.org/sites/default/files/2017-01/Unido_industry-4_NEW_0.pdf.

US FTC. 2015. 'Internet of Things, Privacy and Security in a Connected World'. https://www.ftc.gov/system/files/documents/reports/federal-trade-commission-staffreport-november-2013-workshop-entitled-internet-things-privacy/150127iotrpt.pdf.

US Senate. 2017. 'Internet of Things Cybersecurity Improvement Act'. https://www.congress.gov/bill/115th-congress/senate-bill/1691/text?format=txt.

Woolf, Nicky. 2016. 'DDoS Attack That Disrupted Internet Was Largest of Its Kind in History, Experts Say'. The Guardian. 26 October 2016. http://www.theguardian.com/technology/2016/oct/26/ddos-attack-dyn-mirai-botnet. 